Tjalling C. Koopmans Research Institute Tplligl Aoopman

Discussion Paper Series nr: 12-07

\title{
Mean Reversion in Stock Prices: Implications for Long-Term Investors
}

Laura Spierdijk Jacob A. Bikker 


\section{Tjalling C. Koopmans Research Institute Utrecht School of Economics Utrecht University}

Kriekenpitplein 21-22

3584 EC Utrecht

The Netherlands

$\begin{array}{ll}\text { telephone } & +31302539800 \\ \text { fax } & +31302537373 \\ \text { website } & \text { www.koopmansinstitute.uu.nl }\end{array}$

The Tjalling C. Koopmans Institute is the research institute and research school of Utrecht School of Economics.

It was founded in 2003, and named after Professor Tjalling C. Koopmans, Dutch-born Nobel Prize laureate in economics of 1975.

In the discussion papers series the Koopmans Institute publishes results of ongoing research for early dissemination of research results, and to enhance discussion with colleagues.

Please send any comments and suggestions on the Koopmans institute, or this series to J.M.vanDort@uu.nl

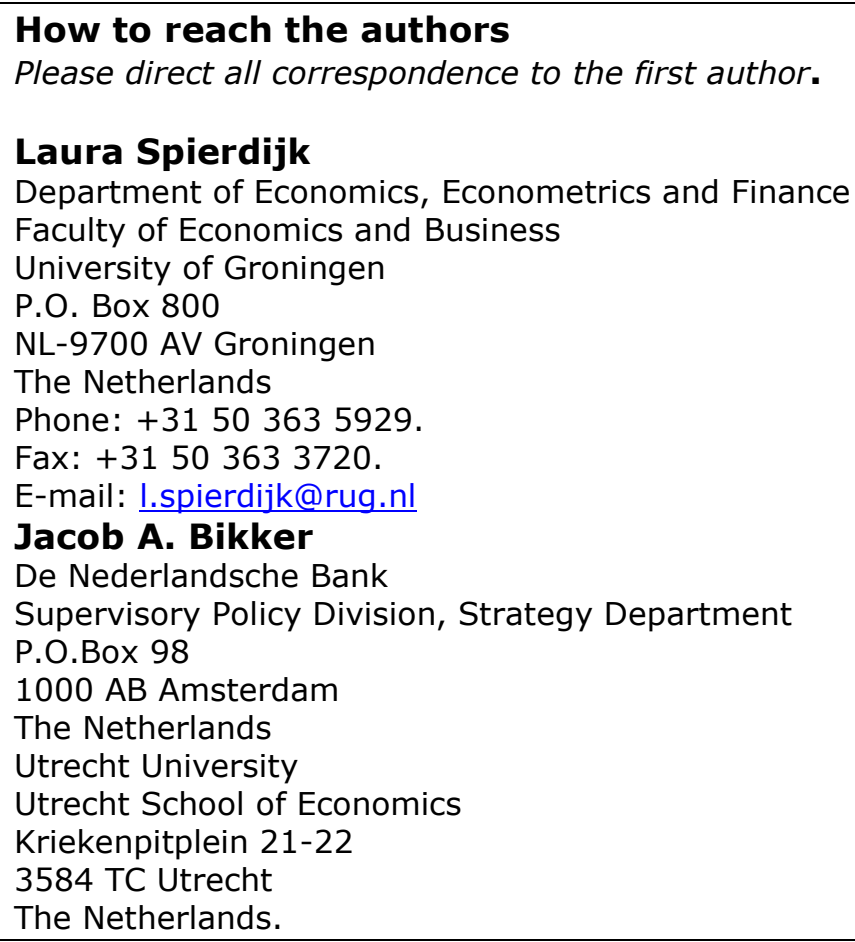

This paper can be downloaded at: http:// www.uu.nl/rebo/economie/discussionpapers 
Utrecht School of Economics

Tjalling C. Koopmans Research Institute

Discussion Paper Series 12-07

\title{
Mean Reversion in Stock Prices: Implications for Long-Term Investors
}

\author{
Laura Spierdijk $k^{a}$ \\ Jacob A. Bikker ${ }^{\text {b }}$ \\ ${ }^{a}$ Faculty of Economics and Business \\ University of Groningen \\ ${ }^{\text {b }}$ Supervisory Policy Division, Strategy Department \\ De Nederlandsche Bank \\ Utrecht School of Economics \\ Utrecht University
}

April 2012

\begin{abstract}
This paper discusses the implications of mean reversion in stock prices for longterm investors such as pension funds. We start with a general definition of a meanreverting price process and explain how mean reversion in stock prices is related to mean reversion in stock returns. Subsequently, we show that mean reversion makes stocks less risky for investors with long investment horizons. Next, we consider a mean-variance efficient investor and show how mean reversion in stock prices affects such an investor's optimal portfolio weights. Finally, we discuss the implications of our findings for the investment decisions of long-term investors.
\end{abstract}

Keywords: mean-variance efficiency, optimal portfolio weights, pension funds, riskaversion, variance of stock returns.

JEL classification: G11, G12, G23. 


\section{Introduction}

A widely held belief in economics is that what goes up, must come down - eventually (De Bondt 1991). In terms of stock prices this belief translates into the concept of (longrun) mean reversion, which states that a decline in stock prices is most likely to be followed by an upward price movement, and vice versa.

The presence or absence of mean reversion has important economic implications. Because mean reversion in stock prices induces negative autocorrelation in stock returns (a result that will be derived in Section 4), the variance of stock returns is less than proportional to the investment horizon. The relatively low long-term volatility increases the attractiveness of stocks as a long-term investment (which we will illustrate in Section 5). Furthermore, if stock prices are mean-reverting in the long run, low stock prices are followed by relatively high expected future returns, which could encourage long-term investors such as pension funds to invest in equity after a stock market downturn (Vlaar 2005). Indeed, some studies propose trading strategies based on mean reversion in stock prices to generate excess returns (Balvers et al. 2000, Gropp 2004).

Several theories have been put forward to explain mean reversion in stock prices. These explanations hinge on the tenet of market efficiency. The efficient market hypothesis states that all available information is reflected in the value of a stock (Fama 1991). Mean reversion in stock prices may reflect market inefficiency. According to Poterba \& Summers (1988), mean reversion may be caused by the irrational behavior of noise traders, resulting in stock prices that take wide swings away from their fundamental value. Irrational pricing behavior, in turn, can be caused by fads (McQueen 1992, Summers 1986), overreaction to financial news (De Bondt \& Thaler 1985, 1987) or investor's opportunism (Poterba \& Summers 1988). However, stock price mean reversion does not necessarily contradict market efficiency (Fama \& French 1988a). Assuming that all available information is incorporated into stock prices, the value of a stock 
is determined by the expected returns per share. Consequently, mean reversion is observed when expected returns are mean-reverting (Summers 1986). In an empirical study, Conrad \& Kaul (1988) find that the time-varying process of a stock's expected return reverts back to its mean over time. Fluctuations in expected returns may be explained from uncertainty about the survival of the economy, caused by e.g. a world war or a depression (Kim et al. 1991). Alternatively, they can be caused by rational speculative bubbles or uncertain business prospects (McQueen 1992). Alternative explanations for mean reversion in stock prices have been provided by, among others, Chan (1988), Ball \& Kothari (1980), Zarowin (1990), Conrad \& Kaul (1993), and Ball et al. (1995).

After the seminal studies by Summers (1986), Poterba \& Summers (1988), and Fama \& French (1988a) an ongoing debate has emerged in the literature as to whether stock prices and stock returns are mean-reverting or not. The substantial amount of recent publications in this field (Ang \& Bekaert 2007, Goyal \& Welch 2008, Boudoukh et al. 2008, Pastor \& Stambaugh 2009, 2011, Spierdijk et al. 2012) illustrates that the meanreverting behavior of stocks is still an important issue. The cause of the debate lies in the fact that testing for mean reversion is inherently difficult due to a lack of historical data on stock prices. Accurate estimation of the degree of long-run mean reversion requires very long stock price series, which are not available. For example, if stock prices were to revert back to their fundamental value every twenty years, one would need at least 1,000 to 2,000 yearly observations to obtain reliable estimations. Moreover, the likely structural breaks during long sample periods further complicate statistical analysis of mean reversion (Spierdijk et al. 2012). These methodological difficulties explain why mean reversion is a controversial issue in the economic literature.

The goal of this paper is not to provide a final answer to the question whether stock prices and returns are mean-reverting or not. Instead, we aim at making investors aware of the economic consequences of mean-reverting behavior of stocks. The remainder of this 
paper therefore focuses on describing relevant properties of mean-reverting stock prices and the resulting implications for long-term investors such as pension funds.

The set-up of this paper is as follows. Section 2 provides a formal definition of mean reversion in stock prices, based on the seminal work of Summers (1986). A detailed overview of the mean reversion literature appears in Section 3. Section 4 calculates the volatility and autocovariances function of single-period and multi-period returns in the presence of mean reversion. Because the variance of stock returns is related to the associated investment risk, single-period and multi-period variances and autocovariances contain crucial information for investors. This section also explains how mean reversion in stock prices is related to mean reversion in stock returns. Furthermore, we show how the concept of mean reversion is related to the concept of covariance-stationarity. In Section 5 we consider a mean-variance efficient investor with an investment horizon of up to 20 years and investigate the implications of mean reversion in stock prices for optimal asset allocation and the profitability of trading strategies. Finally, we conclude in Section 6.

\section{Definition of mean reversion stock prices}

This section describes the stock price model of Summers (1986), which allows for mean reversion in stock prices; see also Poterba \& Summers (1988) and Fama \& French (1988a). This model provides a convenient and discriptive framework for the mean-reverting behavior of stock prices, as we will explain in detail later in this section.

\subsection{Permanent and transitory price components}

Summers (1986) defines a mean-reverting $\log$ price process $p_{t}$ as the sum of a permanent and a transitory component:

$$
p_{t}=p_{t}^{*}+z_{t}
$$


The permanent component $p_{t}^{*}$ models the intrinsic value of a stock, whereas $z_{t}$ represents a slowly decaying covariance-stationary price component. ${ }^{1}$ It is assumed that $p_{s}^{*}$ and $z_{t}$ are uncorrelated for all $s$ and $t$. As an example, Summers (1986) models $z_{t}$ according to a first-order autoregressive model $^{2}$,

$$
z_{t}=\mu+\phi z_{t-1}+\eta_{t}
$$

with $\mu$ the intercept, $0<\phi<1$ the autoregressive (persistence) parameter and $\eta_{t}$ white noise with variance $\sigma^{2}$. A shock to the permanent component $p_{t}^{*}$ at time $t$ is immediately incorporated into the future stock price. In contrast, a price shock through the transitory component $z_{t}$ will slowly decay towards zero over time. Fama \& French (1988a) specify the underlying intrinsic value process $p_{t}^{*}$, satisfying

$$
p_{t}^{*}=p_{t-1}^{*}+\delta_{t}
$$

where $\delta_{t}$ is white noise with variance $\tau^{2}$. It is assumed that $\eta_{s}$ and $\delta_{t}$ are independent for all $s$ and $t$. The transitory price component induces mean reversion in the (log) stock price. To make the stock price's mean-reverting behavior more directly observable, one may rewrite Equation (1) as

$$
p_{t}=\tilde{\mu}+\tilde{p}_{t}^{*}+\phi\left(z_{t-1}-\left(\tilde{\mu}+\tilde{p}_{t}^{*}\right)\right)+\eta_{t},
$$

which tells us that the price process $p_{t}$ is mean-reverting around the value $\tilde{\mu}+\tilde{p}_{t}^{*}$, where $\mu /(1-\phi)$ equals the long-run mean of the transitory price component and $\tilde{p}_{t}^{*}=p_{t}^{*} /(1-$ $\phi)$.

A convenient way to characterize the speed of mean reversion is the half-life. The

\footnotetext{
${ }^{1} \mathrm{~A}$ time series $z_{t}$ is covariance-stationary if its mean, variance and autocovariance function are finite and constant over time; i.e. if $\mathbb{E}\left(z_{t}\right)=\mu<\infty$, $\operatorname{Var}\left(z_{t}\right)=\sigma^{2}<\infty$ and $\operatorname{Cov}\left(r_{t}, r_{t+k}\right)=\gamma_{k}$.

${ }^{2} \mathrm{An} \operatorname{AR}(1)$ process is covariance-stationary if and only if $|\phi|<1$.
} 
half-life associated with the price process in Equation (1) is defined as the number of periods it takes $z_{t}$ to absorb half of a unit shock. The first-order autoregressive structure of $z_{t}$ ensures that the half-life has a closed-form solution; it equals $h=\log (0.5) / \log (\phi)$ (Kim et al. 2007), which is properly defined for $0<\phi<1$. For example, with $\phi=0.8$ the half-life equals 3.1 periods.

The parameter $\phi$ plays an important role as it determines the speed of mean reversion, but the variances $\tau^{2}$ (corresponding to the permanent price component) and $\sigma^{2}$ (transitory price component) are crucial as well. If the variance of the permanent price component is much larger (smaller) than the variance of the transitory component, the latter plays a less (more) important role, resulting in weak (strong) mean reversion. We will make these relations more precise in Section 4.

\subsection{Generalization}

Although the mean-reverting price process defined by Equations (1), (2), and (3) may seem restrictive, it is more general than is apparent at first sight. This generality explains the model's suitability as a tool for describing the mean-reverting behavior of stock prices.

To allow the price process to be consistent with the efficient market hypothesis, the random walk should be nested in the specification for the stock price. This explains why the permanent price component in Equation (1) is chosen to be a random walk. The price process in Equation (1) follows a random walk for $\phi=1$, but deviates from the efficient market hypothesis for $0<\phi<1$. Hence, only the choice for a first-order autoregressive (AR) process could possibly be restrictive. A seemingly more general specification defines $z_{t}$ in Equation (1) as a covariance-stationary, mean-reverting process with mean 0. But every covariance-stationary series can be written as an moving average (MA) process of infinite order - a result known as Wold's decomposition theorem. If the MA process is invertible, it can be written as an AR process of infinite order, which brings us one step 
closer to our AR(1) process. The only restrictive aspect of the first-order AR process is its order.

We may therefore want to consider a generalization of the previously considered mean-reverting price process by relaxing the assumption of a first-order AR process for the transitory price component. Instead of an $\operatorname{AR}(1)$ process we could assume an $\operatorname{AR}(p)$ process as approximation of an AR process of infinite order, for any $p=1,2, \ldots$.

With $z_{t}$ equal to a higher-order autoregressive model, the half-life is more difficult to calculate. It can be obtained from the impulse response function corresponding to a unit shock in $z_{t}$. If $\alpha_{i}$ represents the impulse response of $z_{t+i}$ to a unit shock in $z_{t}$ at time $t(i=$ $1,2, \ldots)$, then the half-life $h$ is calculated as the largest value $j$ which satisfies $\alpha_{j-1} \geq 0.5$ and $\alpha_{j}<0.5$. When $j$ lies between two consecutive integer values, linear interpolation is used to determine the value of $h$. Notice that the impulse responses coincide with the coefficients of the infinite-order MA representation of the AR model.

The ability of the stock price model of Summers (1986) to allow for mean reversion in stock prices, in combination with the simplicity of the specification based on a first-order autoregressive transitory price component (particularly the straightforward expression for the half-life), explains why most studies confine the analysis of the transitory price process to a first-order autoregressive model. We will elucidate the statistical properties of the mean reversion model in Section 4, but first we will review the literature.

\section{Literature}

Since the seminal studies by Summers (1986), Poterba \& Summers (1988), and Fama \& French (1988a) an ongoing debate has emerged in the literature as to whether stock prices are mean-reverting or not. Testing for mean reversion is inherently difficult because of the limited supply of historical data on stock prices. Accurate estimation of the degree of long-run mean reversion requires very long data series, which are not available. 
It is possible to make use of monthly overlapping returns to increase the number of observations, but this leads to serious statistical problems (as we will explain in Section 3.1). Moreover, structural breaks in the behavior of stock prices are likely to occur during long sample periods, complicating the statistical analysis of mean reversion (Spierdijk et al. 2012). These issues explain why, even after twenty years of mean reversion research, it is still difficult quantify the degree of mean reversion in stock prices.

Two different methods have been used in the literature to test for mean reversion. The first approach tests for mean reversion in a way that does not require estimation of the fundamental value process $p_{t}^{*}$ in Equation (1). This method is known as the approach of absolute mean reversion. The second method proceeds in a different way and starts with the estimation of the fundamental value process $p_{t}^{*}$. This method is referred to as relative mean reversion, because it has stock prices reverting relative to a specified mean value. We will explain both methods in more detail in this section. We will also review some recent studies analyzing mean reversion in stock returns.

\subsection{Absolute mean reversion}

Fama \& French (1988a) derive a regression model to test whether the autocorrelation pattern in stock returns is consistent with the model defined by Equations (1), (2) and (3). For values of $\phi$ close to unity, the negative autocorrelation in stock returns is stronger for long-horizon than for short-horizon returns. Fama \& French (1988a) therefore examine several investment horizons between one and ten years. This approach establishes significant mean reversion, explaining $25 \%-40 \%$ of the variation in the $3-5$ year stock returns.

Poterba \& Summers (1988) use a specific property of the random walk to test for mean reversion. Mean reversion of stock prices implies that the variance of stock returns grows less than proportionally with time. Poterba $\&$ Summers (1988) apply the variance-ratio 
test of Cochrane (1988) to detect this implication of mean reversion. The $m$-year variance ratio is defined as the ratio of the $m$-year return variance to the one-year return variance, divided by $m$. When this ratio is equal to one, the random walk hypothesis cannot be rejected. Poterba \& Summers (1988) find mean reversion over long investment horizons in the United States. Similar results have been established for several developed countries. The lack of significance in their results is attributed to the absence of more powerful tests to reject the null hypothesis.

Both Fama \& French (1988a) and Poterba \& Summers (1988) analyze the period from 1926 to 1985 and work with yearly overlapping stock returns to increase the number of observations. The issue of dependence, which is inherent in the use of overlapping observations, is resolved by applying the method of Hansen \& Hodrick (1980). Richardson \& Smith (1991) criticize this approach and address the problem of small-sample bias. They show that the evidence supporting long-term mean reversion disappears if they remove the small-sample bias. Moreover, Richardson \& Stock (1990) argue that the use of a larger overlapping interval at longer investment horizons increases the power of the statistical tests used to test the random walk hypothesis. Their more powerful statistical test does not result in a rejection of the random walk hypothesis. Jegadeesh (1991) raises the issue of seasonality caused by the use use of monthly overlapping stock returns.

Apart from these latter issues, the approach of Fama \& French (1988a) has come in for other types of criticism as well. McQueen (1992) addresses the issue of heteroskedasticity in the sample period. The highly volatile years tend to have a larger influence on the results because of their relatively heavy weights. McQueen (1992) finds that the highly volatile periods exhibit stronger mean-reverting tendencies and that the overall evidence for mean reversion is therefore overstated. Kim \& Nelson (1998) and Kim et al. (1998) criticize Fama \& French (1988a) and Poterba \& Summers (1988) on similar grounds. The issue of heteroskedasticity is directly linked to another point of criticism. Past periods of high 
volatility may not be representative of current stock price behavior. Poterba $\&$ Summers (1988) note that the Great Depression exerts substantial influence on the estimates of the mean-reversion parameters. Excluding this period considerably weakens the evidence for mean reversion. Kim et al. (1991) divide the total sample period into a period before and a period after World War II and conclude that mean reversion is a pre-World War II phenomenon only. Furthermore, the post-war period reveals mean aversion, indicating a structural break in stock price behavior. ${ }^{3}$

\subsection{Relative mean reversion}

The lack of evidence for mean reversion is often attributed to small sample sizes in combination with statistical tests for mean reversion that lack power. A substantial improvement in estimation accuracy may be achieved by explicitly specifying the fundamental value process (called the benchmark) around which the mean reversion occurs. The important question here is how to proxy the fundamental value process, which is inherently unobserved. According to the Gordon growth model, the value of a stock equals the discounted future cash flows generated by the stock (Gordon 1959). In practice, these cash flows are the dividends to be paid out to the owners. Instead of estimating future dividends, one may use earnings as a proxy of future cash flows towards investors. Other possible proxies are valuation ratios, such as dividend yield or price-earnings ratios.

Campbell \& Shiller (2001) examine the mean-reverting behavior of dividend yields and price-earnings ratios over time. Theoretically, these variables are expected to be mean-reverting, since fundamentals are determinants of stock prices. If stock prices are high in comparison to company fundamentals, an adjustment to either stock prices or fundamentals may be expected. Campbell \& Shiller (2001) find that adjustment of the ratios towards an equilibrium level is driven more by stock prices than by company fundamen-

\footnotetext{
${ }^{3}$ Mean aversion is movement of stock prices away from their mean value over time.
} 
tals. Coakley \& Fuertes (2006) consider the mean-reverting behavior of valuation ratios and attribute it to differences in investor sentiment. The authors conclude that financial ratios revert to their long-term average value. In earlier work, Fama \& French (1988b) link the dividend yield to the expected returns on a stock and find that the latter have a mean-reverting tendency.

A second specification of fundamental value is based on asset pricing models. Ho \& Sears (2004) link the mean-reverting behavior of stocks to the Fama-French three-factor model and conclude that such models cannot capture the mean-reverting behavior of stock prices. Similar conclusions emerge from Gangopadhyay \& Reinganum (1996). However, they argue that mean reversion can be explained by the CAPM if the market risk premium is allowed to vary over time. Note that this fluctuation is in accordance with the theoretical explanation of mean reversion in efficient markets; expected returns fluctuate in a mean-reverting manner (Summers 1986). Gropp (2004) argues that valuation ratios are inherently flawed, because information on company fundamentals cannot be compared to stock prices due to the delay in adjustment. Expected future dividends and earnings influence a stock's fundamental value, which cannot be captured by the current dividend yield or the price-earnings ratio. Moreover, the loss of information due to the use of proxies may contribute to the failure to recognize mean-reverting behavior.

According to Balvers et al. (2000), the stationary relation between the fundamental value of a stock and a benchmark index permits direct assessment of the speed of mean reversion. Moreover, they use annual rather than monthly data to avoid the problem of seasonality. To estimate the mean-reversion process more accurately, Balvers et al. (2000) adopt a panel data approach. Comparing the real stock price indices of 18 countries to a world index benchmark during the 1970 - 1996 period, they establish significant mean reversion, with a half-life of approximately 3.5 years. The half-life measures the period it takes stock prices to absorb half of a shock. Balvers et al. (2000) find a 90\% confidence 
interval for the half-life equal to $[2.4,5.9]$ years.

In a related study, Spierdijk et al. (2012) analyze mean reversion in the stock markets of 18 OECD countries during the years 1900 - 2009. In this period it takes stock prices about 18.5 years, on average, to absorb half of a shock. However, using a rollingwindow approach they establish large fluctuations in the speed of mean reversion over time. Their analysis suggests that the speed at which stocks revert to their fundamental value is faster in periods of high economic uncertainty, caused by major economic and/or political events. The highest mean reversion speed is found for the period including the Great Depression and the start of World War II. Furthermore, the early years of the Cold War and the period containing the Oil Crisis of 1973, the Energy Crisis of 1979 and Black Monday in 1987 are also characterized by relatively fast mean reversion. During periods with relatively low economic uncertainty, mean reversion is virtually absent; i.e, the speed of mean reversion is very slow and subject to high estimation uncertainty. Overall, they document half-lives ranging between 2.0 and 22.6 years.

\subsection{Mean reversion in stock returns}

Many recent studies investigate predictability of stock returns (Ang \& Bekaert (2007), Goyal \& Welch (2008), Boudoukh et al. (2008), Pastor \& Stambaugh $(2009,2011))$. Predictability of stock returns from dividends or other fundamental factors may give rise to negative autocorrelation in stock returns. Negative autocorrelation in stock returns is generally referred to in the literature as mean reversion in stock returns. The empirical evidence for mean reversion in stock returns is also thin. In Section 4.4 we will show that mean reversion in stock price implies mean reversion in stock returns, but that generally, the reverse is not true: mean reversion in stock returns does not necessarily imply mean reversion in stock prices. In this paper we will mainly focus on mean reversion in stock prices because the latter type of mean reversion implies the former. 


\subsection{Where do we stand?}

The literature has found little evidence for long-run mean reversion in stock prices while the evidence for mean reversion in stock returns is also thin. The substantial number of recent publications in this field illustrates the ongoing debate among economists about the mean-reverting behavior of stocks. As explained in the introduction of this paper, it is not our goal to provide a final answer to the question whether stock prices or returns are mean-reverting or not. Instead, we want to make investors aware of the implications of mean-reverting behavior in stocks. The remainder of this paper therefore focuses on the implications of mean reversion for long-term investors such as pension funds.

\section{Properties of multi-period returns}

This section calculates variances and autocovariances of single-period and multi-period stock returns in the presence of mean reversion in stock prices. Because the variance of stock returns is associated with the investment risk associated with this asset class, singleperiod and multi-period variances contain crucial information for investors.

\subsection{One-period returns}

In the framework of Section 2, the restriction $0<\phi<1$ induces negative autocorrelation in one-period log stock returns $r_{t}=p_{t}-p_{t-1}$, because for $k=1,2, \ldots$ :

$$
\begin{aligned}
\gamma_{k}\left(r_{t}\right) & =\mathbb{C o v}\left(r_{t}, r_{t+k}\right) \\
& =\mathbb{C o v}\left(\Delta p_{t}^{*}+\Delta z_{t}, \Delta p_{t+k}^{*}+\Delta z_{t+k}\right) \\
& =\operatorname{Cov}\left(\Delta p_{t}^{*}, \Delta p_{t+k}^{*}\right)+\operatorname{Cov}\left(\Delta z_{t}, \Delta z_{t+k}\right) \\
& =\frac{-\sigma^{2} \phi^{k-1}(1-\phi)}{1+\phi}<0 .
\end{aligned}
$$


The function $\gamma_{k}\left(r_{t}\right)$ is called the autocovariance function of $r_{t}$. The one-period return variance equals

$$
\gamma_{0}\left(r_{t}\right)=\tau^{2}+\frac{\sigma^{2}}{\phi(2-\phi)}
$$

Throughout, $z_{t}$ represents a covariance-stationary process for $0<\phi<1$ with autocovariance function

$$
\gamma_{k}\left(z_{t}\right)=\sigma^{2} \phi^{k} /\left(1-\phi^{2}\right) . \quad[k,=0,1,2, \ldots]
$$

We see that, for $k$ tending to infinity, $\gamma_{k}\left(r_{t}\right)$ decays geometrically to 0 for $0<\psi<1$. This means that the negative correlation between $r_{t}$ and $r_{t+k}$ diminishes with $k$. Hence, two returns are virtually uncorrelated if they are sufficiently apart in time. Also, if $\phi$ approaches unity (reflecting a very slow speed of mean reversion), $\gamma_{k}\left(r_{t}\right)$ tends to zero. The same holds for $\phi$ close to 0 , in which case the transitory price process approaches white noise, with no mean reversion. Furthermore, the higher the variance of the transitory price process $\sigma^{2}$, the more dominant the transitory price component relative to the permanent component and the more negative $\gamma_{k}\left(r_{t}\right)$. These relations illustrate that both $\phi$ and $\sigma^{2}$ (and particularly $\sigma^{2}$ relative to $\tau^{2}$ ) determine the mean-reverting behavior of stock prices.

\subsection{Multi-period returns}

From the perspective of a long-term investor, we may also be interested in multi-period

returns. For the (non-overlapping) $m$-period returns $r_{t}(m)=\sum_{j=1}^{m} r_{t+j}$, we calculate the 
first-order autocovariance, yielding

$$
\begin{aligned}
\gamma_{1}\left(r_{t}(m)\right) & =\operatorname{Cov}\left(r_{t}(m), r_{t+m}(m)\right) \\
& =\operatorname{Cov}\left(\sum_{i=1}^{m} r_{t+i}, \sum_{j=m+1}^{2 m} r_{t+j}\right) \\
& =\sum_{i=1}^{m} \sum_{j=m+1}^{2 m} \operatorname{Cov}\left(r_{t+i}, r_{t+j}\right) \\
& =\sum_{i=1}^{m} \sum_{j=m+1}^{2 m} \gamma_{j-i}\left(r_{t}\right)<0,
\end{aligned}
$$

because $\gamma_{j-i}\left(r_{t}\right)<0$. Similarly, also the higher-order autocovariances turn out negative.

Also of interest to a long-term investor is the variance of the $m$-period returns. For $m=2,3, \ldots$ we find

$$
\begin{aligned}
\gamma_{0}\left(r_{t}(m)\right) & =\operatorname{Var}\left(r_{t}(m)\right) \\
& =m \gamma_{0}\left(r_{t}\right)+\sum_{j=1}^{m} \sum_{i=1}^{j-1} \gamma_{j-i}\left(r_{t}\right)
\end{aligned}
$$

For $\sigma^{2}>0$ and $0<\phi<1$, we find $\gamma_{0}\left(r_{t}(m)\right)<m \gamma_{0}\left(r_{t}\right)$. With mean reversion in stock prices, the variance of the $m$-period returns is smaller than $m$ times the one-period variance; the variance increases less than proportionally with the investment horizon. Hence, for long investment horizons stocks are relatively less risky than for short horizons.

\subsection{Higher-order AR model}

For an $\operatorname{AR}(p)$ process, introduced in Section 2.2, the derivations in Sections 4.1 and 4.2 remain the same. The only aspect we have to adjust is the autocovariance function. An $\operatorname{AR}(p)$ process of the form

$$
z_{t}=\phi_{1} z_{t-1}+\phi_{2} z_{t-2}+\ldots+\phi_{k} z_{t-p}+\eta_{t}
$$


is characterized by the recursive autocovariance function

$$
\gamma_{k}\left(z_{t}\right)=\sum_{j=1}^{p} \phi_{j} \gamma_{|k-j|}\left(z_{t}\right) \quad[k=1,2, \ldots]
$$

and variance

$$
\gamma_{0}\left(z_{t}\right)=\sum_{j=1}^{p} \phi_{j} \gamma_{j}\left(z_{t}\right)+\sigma^{2}
$$

We see that the sign of the autocovariances depends crucially on the AR coefficients $\phi_{1}, \ldots, \phi_{p}$. If the autocovariance function remains positive at all lags, the main conclusions of the analysis in Sections 4.1 and 4.2 will remain unaffected.

\subsection{Mean reversion in prices vs mean reversion in returns}

In the model of Equations (1), (2), and (3), the negative autocorrelation in stock returns (cf. Equations (5) and (10)) is a direct consequence of the mean-reverting behavior of the underlying stock price. The converse is not true: negative autocorrelation in stock returns generally does not imply the presence of mean reversion in stock prices. We illustrate this property with the following example. The fundamental value process $p_{t}^{*}$ is taken to be a series of iid random variables with a Cauchy distribution, whereas the transitory price component follows an arbitrary covariance-stationary AR(1) model, independent from the fundamental value process. ${ }^{4}$ Because the mean of the Cauchy does not exist (it is not finite), the price process is not mean-reverting. Admittedly, the example is empirically not very relevant, but it illustrates our main point. The return process (i.e. log price differences) generally does not uniquely determine the price process (i.e. log price levels).

\footnotetext{
${ }^{4}$ The (standard) Cauchy distribution has probability density function $f(x)=1 /\left(\pi\left(1+x^{2}\right)\right)$.
} 


\subsection{The relation between mean reversion and covariance-stationarity}

A property related to mean reversion is covariance-stationarity. The properties of mean reversion (in the sense of Summers (1986)) and covariance-stationarity are equivalent in an $\operatorname{AR}(k)$ model. To prove this equivalence, we assume that the process $p_{t}$ follows a covariance-stationary AR(1) model of the form

$$
p_{t}=\mu+\phi p_{t-1}+\eta_{t}
$$

Alternatively, we can write $p_{t}$ as the sum of a permanent price component and a transitory price component:

$$
p_{t}=\tilde{\mu}+z_{t}
$$

where $\tilde{\mu}=1 /(1-\phi)$ and $z_{t}=\phi z_{t-1}+\eta_{t}$. Notice that the assumed covariance-stationarity of $p_{t}$ ensures the existence of the long-run mean $\tilde{\mu}$. From Equation (15) we see that $p_{t}$ is mean-reverting in the sense of Summers (1986), with the fundamental value process equal to $\tilde{\mu}$. Conversely, if the $\operatorname{AR}(1)$ process is mean-reverting in the sense of Summers (1986), the fundamental value process has to be equal to $0<\tilde{\mu}<\infty$, which requires $0<\phi<1$; i.e. covariance-stationarity.

In models outside the class of $\operatorname{AR}(k)$ models the concepts of mean reversion and covariance-stationarity are not necessarily equivalent. We illustrate this with the (stylized) fundamental value process depicted in Figure 1, which increases linearly over time. The (stylized) price process moves around the fundamental value. Evidently, the stock price is not mean-stationary (and thereby not covariance-stationary), yet it is mean-reverting around the fundamental value process in the sense of Summers (1986) and Fama \& French (1988a). Conversely, it is easy to find a covariance-stationary process that is not meanreverting. The simplest example is a series of iid normally distributed variables. 


\section{Mean reversion and mean-variance efficient portfolios}

This section assesses the economic implications of mean reversion in stock prices for long-term investors. The starting point is a mean-variance efficient investor that determines its optimal portfolio weights solely on the basis of the mean and covariance structure of the asset returns in its investment set. A mean-variance efficient investor will hold the portolio with the lowest volatility for a given level of the expected portfolio return, or the portfolio with the highest expected return for a given level of the portfolio volatility.

\subsection{Outline}

We consider a long-term investor that wants to divide its wealth between stocks and bonds in mean-variance optimal proportions. We consider investment horizons ranging between $1,5,10$, and 20 years. To construct an empirically relevant example, we base the parameter values on historical data.

\subsubsection{Expected returns and volatilities of stocks and bonds}

We assume the following values, corresponding to monthly stock returns (in the notation of Section 2): $\mu=0.9 \%$ (expected return of stocks), $\phi=0.975$ (reflecting a speed of mean reversion of 2.3 years), $\sigma=3.2 \%$ (volatility of the error term in the transitory price component), and $\tau=3.2 \%$ (volatility of the error term of the permanent price component). These parameters correspond to a monthly standard deviation of $4.5 \%$, a figure that is based on the Datastream U.S. Aggregate Stock Market Index during the period from January 1982 until August 2010. For the bond index we assume a monthly expected return of $0.7 \%$ and a volatility of $1.4 \%$, which has been based on the historic performance of the Citigroup U.S. Overall Bond Investment Grade Total Return Index during the same period. The latter index is investable through various Exchange Traded Funds and Exchange Traded Notes. To isolate the effect of mean reversion in stock prices 
on the optimal portfolio weights, we exclude a priori the presence of mean reversion in the bond returns.

\subsubsection{Correlation between stock and bond returns}

The monthly contemporaneous correlation between the stock and bond indices is assumed to be 0.2 , which equals the historical correlation between the aforementioned stock and bond indices during the sample period. The contemporaneous multi-period correlations are assumed to be 0.18 (one year), 0.17 (5 years), 0.17 (10 years), and 0.17 (20 years). ${ }^{5}$

\subsubsection{Risk-free yield curve}

The risk-free rate is based on the nominal interest rate term-structure as compiled by the Dutch Central Bank. ${ }^{6}$

\subsubsection{Variance ratio of permanent and transitory returns}

We assume that the variance of the permanent and transitory price components contribute equally to the total stock return variance - a choice that has been motivated by the results documented in Poterba \& Summers (1988). In the subsequent analysis we define the variance ratio as the return variance of the permanent price component divided by the return variance of the transitory component. ${ }^{7}$ Later we will address the influence of the variance ratio by means of a sensitivity analysis. ${ }^{8}$

\footnotetext{
${ }^{5}$ These figures have been obtained by applying the Vector Autoregression methodology of Hodrick (1992) to the aforementioned stock and bond indices. The approach proposed by Hodrick (1992) provides a robust alternative to methods based on overlapping stock returns.

${ }^{6}$ URL: http://www.statistics.dnb.nl/popup.cgi?/usr/statistics/excel/t1.3nm.xls.

${ }^{7}$ More formally, the variance ratio is equal to $\frac{\tau^{2}}{\sigma^{2} /(\phi(2-\phi))}$; cf. Equation (6).

${ }^{8}$ We do not use our own stock price series to estimate the variance ratio, because reliable estimation of the variance ratio requires very long data series. Our own series spans less than thirty years, which is much too short. We therefore base our choice of the variance ratio on the literature.
} 


\subsection{Optimal portfolio weights}

The right-hand-side panel in the upper half of Table 1 (captioned 'variance ratio $=1: 1$ ') displays optimal stock and bond allocations for investment horizons between one and ten years. The optimal portfolios that we consider explicitly are the global minimum variance portfolio (GMVP) and the tangency portfolio (TP). The GMVP is the mean-variance efficient portfolio with the lowest portfolio volatility, whereas the TP is the mean-variance efficient portfolio with highest possible risk-adjusted excess return. Figure 2 displays the TP and GMVP in the mean-variance space. According to the Capital Asset Pricing Model, investors invest their wealth in a combination of the risk-free rate and the tangency portfolio.

Without mean reversion in stock returns (see the lower half of Table 1), the optimal portfolio weights are nearly independent from the investment horizon. This is because the mean and variance of both stock and bond returns increase proportionally with the investment horizon. A negligible horizon effect is induced by the risk-free rate that increases non-proportionally with the investment horizon and by the correlation between stock and returns that varies slightly over the investment horizon. With mean reversion in stock prices (see the upper half of Table 1), the variance of stock returns increases less than proportionally, making stocks more attractive for longer investment horizons. This explains why we observe a small increase in the optimal portfolio weights assigned to stocks for longer investment horizons. For the GMVP the maximum difference in stock allocations with and without mean reversion is less than 2.5 percentage points, while for the TP the maximum difference is less than 2 percentage points. All in all, the results in Table 1 make clear that the optimal portfolio allocations are not very sensitive to the presence of stock price mean reversion. 


\subsection{Realistic portfolio weights for pension funds}

For Dutch pension funds the optimal portfolio weights obtained in Section 5.2 are not very realistic. Therefore we also consider a pension fund that invests $50 \%$ of its wealth in stocks and $50 \%$ in bonds. The equal division between stocks and bonds corresponds to the so-called standard asset allocation in the Dutch Financial Assessment Framework (FTK) for pension funds. The left-hand panel of Table 2 (captioned 'variance ratio $=1: 1$ ') displays the resulting expected portfolio returns and volatilities with and without mean reversion in stock prices (otherwise using the same assumptions as in Section 5.2), again for investment horizons equal to $1,5,10$, and 20 years. With mean reversion in stock prices, the portfolio volatility is lower than without mean reversion, as expected. Yet the differences in portfolio volatility are small; the maximum difference (attained with a 20year investment horizon) is less than 4 percentage points.

\subsection{Sensitivity analysis}

The assumption of mean reversion in stock prices does not substantially affect the optimal portfolio allocations and perceived portfolio risk in Sections 5.2 and 5.3, but this may be due to the choice of parameters in the mean reversion model. We attempted to make these values as realistic as possible by calibrating them from historical data. In this section we perform a sensitivity analysis by altering the parameter choices made in Sections 5.2 and 5.3 .

\subsubsection{Persistence parameter}

One of the parameters responsible for mean reversion in our model is $\phi$, which is directly related to the speed of mean reversion (see Section 2.1). The choice $\phi=0.975$ has been taken from Fama \& French (1988a) who make the same assumption in their simulations. This value of the persistence parameter boils down to a half-life of 27.4 months, or 2.3 
years. Poterba $\&$ Summers (1988) differ only marginally from this and use $\phi=0.98$. Balvers et al. (2000) establish a half-life of 3.5 years, which corresponds to $\phi=0.9836$. Spierdijk et al. (2012) establish time-varying annual values of $\phi$ between and 0.704 and 0.97 (corresponding to monthly values of 0.9712 and 0.9975 , respectively), resulting in half-lives of, respectively, 2 and 23 years.

\subsubsection{Variance ratio}

The other influential parameter in our mean reversion model is the return variance of the transitory price process, in particular in relation to the return variance of the permanent price process. We assumed equal variances in Section 5.2. This assumption was based on Poterba \& Summers (1988), who state that "The point estimates imply that transitory components account for more than half of the monthly return variance, a finding confirmed by international evidence”. However, in their simulations they put the return variance of the transitory price component at three times the return variance of the permanent price process (i.e. a ratio of 1:3), whereas Fama \& French (1988a) use a 1:2 ratio.

\subsubsection{Optimal portfolio weights under different assumptions}

We use aforementioned alternative values for $\phi$ and the variance ratio as input for a sensitivity analysis. Throughout, we calibrate the other parameter values in such as way as to keep the variance of stock returns at $4.5 \%$ on a monthly basis.

It turns out that the value of $\phi$ in the alternative range, as indicated above, leads to much the same output as before. By contrast, the variance ratio has a more substantial influence on the optimal portfolio weights; see the middle and right-hand panel in the upper half of Table 1 (captioned 'variance ratio 1:2' and 'variance ratio 1:3'). The larger the transitory component of stock prices, the stronger their mean reversion. This translates into higher optimal weights for stocks and lower portfolio volatility. The maximum 
difference in the portfolio weights with and without mean reversion is between 2 and 5 percentage points. Similarly, if an investor divides its wealth equally between stocks and bonds, the risk exposure of his portfolio decreases with the variance ratio if we assume that stock prices are mean-reverting; see the middle and right-hand-side panel in the upper half of Table 2 (captioned 'variance ratio 1:2' and 'variance ratio 1:3'). The maximum difference in portfolio volatility with and without mean reversion equals 5.3 percentage points. Obviously, the variance ratio has no influence on the optimal portfolio weights if there is no mean reversion in stock prices (see the lower half of Table 1).

\subsection{The role of the variance ratio}

Our sensitivity analysis shows that the choice of the variance ratio may have substantial impact on investment decisions. If the variance ratio is high - meaning that stock prices are strongly mean-reverting - stocks become relatively less risky in the long run, making it optimal to invest a relatively large share of wealth in stocks. However, if the true variance ratio is lower than the assumed value, the perceived risk exposure is lower than the actual risk exposure. Hence, too much wealth is allocated to stocks, resulting in a non-optimal overexposure to risk.

As noted by Fama \& French (1988a), estimation of the variance ratio is subject to various difficulties. Estimation is only possible in an indirect way and requires very long sample periods owing to the slowly-moving nature of the transitory price component. Available stock return series are relatively short, yielding estimates that suffer from large parameter uncertainty. Accurate assessment of the parameter uncertainty is complicated by the use of overlapping returns - an issue discussed in Section 3.1. Consequently, the true value of the variance ratio remains highly uncertain. If the true variance ratio is $1: n$, with $n$ larger than 3, the effects on portfolio allocation will even be larger than established in Section 5.4.3. 


\subsection{Dealing with uncertainty about the variance ratio}

Given the uncertainty involved with the variance ratio, it is prudent for a risk-averse investor to use a conservative estimate of this ratio. ${ }^{9}$ To see this, suppose that an investor is uncertain about the degree of mean reversion in stock prices. If it overestimates the mean reversion in stock prices, this will result in an overexposure to risk. In an adverse scenario with falling stock prices, this would result in negative investment returns. Conversely, if the investor underestimates stock price mean reversion, it will cause underexposure of risk. Amid rising stock prices, this would result in too low investment returns. Because the investor is risk averse, it will always prefer the risk of earning too low profits over the risk of incurring too high losses. The strength of the investor's preference depends on its degree of risk averseness. For a very risk averse investor it is optimal to base the portfolio weights on an assumption of no or little stock price mean reversion. For an investor that is only little risk averse, by contrast, it is optimal to assume a higher degree of mean reversion. In sum, it is optimal policy for any risk averse investor to make conservative assumptions about the degree of stock price mean reversion. ${ }^{10}$

\subsection{Trading strategies}

Several studies propose trading strategies based on mean reversion in stock prices and show that these strategies yield excess returns; see e.g. Balvers et al. (2000). The latter study establishes a half-life of 3.5 years in a model of relative mean reversion. The au-

\footnotetext{
${ }^{9}$ We mention here that the Dutch Financial Assessment Framework for pension funds requires pension funds to hold capital buffers as to keep the probability of a funding deficit below 2.5 percent. Dutch pension funds are not allowed to base their buffer calculations on the assumption of mean reversion, unless they use the internal model approach and prove that mean reversion is very likely to be present in stock prices or returns. However, Dutch pension funds have not yet pursued this approach. Neither for the continuity test, nor for the cost of covering pension premia pension funds are allowed to assume that stocks become less risky in the long run. Nevertheless, some Dutch pension funds may take mean reversion into account in their investment strategy.

${ }^{10}$ Our argument that it is prudent for a risk averse investor to be conservative about the degree of mean reversion in stock prices can be formalized by means of a Bayesian analysis. This is clearly beyond the scope of this panel paper. We therefore leave this as a topic for future research.
} 
thors consider a contrarian trading strategy (which consists, loosely speaking, of buying past losers en selling past winners; cf. De Bondt \& Thaler (1985)), based on rolling window estimates of the underlying mean reversion model. They show that such a strategy is able to generate (risk-adjusted) excess returns. ${ }^{11}$ Clearly, if stock prices were to follow a random walk, it would not be possible to earn excess returns. Hence not only does the optimal asset allocation affect the degree of stock price mean reversion, but the profitability of trading strategies crucially depends on it as well.

\section{Conclusions}

There has been an ongoing debate as to whether stock prices and stock returns are meanreverting in the long run. This paper has discussed the implications of mean-reverting behavior in stock prices for long-term investors. We showed that the variance of stock returns increases less than proportionally with the investment horizon if stock prices are mean-reverting. Subsequently, we assessed the consequences of stock price mean reversion for mean-variance efficient portfolios. If stock prices are mean-reverting, stocks are relatively less risky for longer investment horizons, so that a larger share of wealth may be allocated to stocks. The same is true if stock returns show negative autocorrelation, which is often referred to in the literature as mean reversion in stock returns (in which case stock prices are not necessarily mean-reverting).

Given the impact of mean-reverting behavior of stocks on asset allocation decisions and the profitability of trading strategies, it is important for investors to know whether or not stock prices and stock returns exhibit mean reversion. Until now, the literature has not yet found strong evidence in favor of mean-reverting behavior, but this may also be due to the difficulties involved in the empirical assessment of mean reversion. Hence, it is

\footnotetext{
${ }^{11}$ We notice that Balvers et al. (2000) do not claim that their contrarian investment strategy is profitable in practice. An explanation for this reservation is that their analysis ignores the issue of transaction costs.
} 
unclear whether stock prices and stock returns are mean-reverting or not. Bearing in mind that the investor will underestimate the risk exposure of stocks if he or she overestimates the degree of mean reversion, it seems prudent for a risk-averse investor to base investment decisions on conservative assumptions regarding the mean-reverting behavior of stocks. 


\section{References}

Ang, A. \& Bekaert, G. (2007), 'Stock return predictability: Is it there?', Review of Financial Studies 20, 651-707.

Ball, R. \& Kothari, S. P. (1980), 'Nonstationary expected returns: Implications for tests of market efficiency and serial correlations in returns', Journal of Financial Economics $25,51-74$.

Ball, R., Kothari, S. P. \& Shanken, J. (1995), 'Problems in measuring performance: An application to contrarian investment strategies', Journal of Financial Economics 38, 79107.

Balvers, R., Wu, Y. \& Gilliland, E. (2000), 'Mean reversion across national stock markets and parametric contrarian investment strategies', Journal of Finance 55, 745-772.

Boudoukh, J., Richardson, M. \& Whitelaw, R. F. (2008), 'The myth of longhorizon predictability', Review of Financial Studies 21, 1577-1605.

Campbell, J. Y. \& Shiller, R. J. (2001), Valuation ratios and the long-run stock market outlook: An update, NBER working papers, National Bureau of Economic Research.

Chan, L. K. C. (1988), 'On the contrarian investment strategy', Journal of Business 61, 147-163.

Coakley, J. \& Fuertes, A.-M. (2006), 'Valuation ratios and price deviations from fundamentals', Journal of Banking \& Finance 30, 2325-2346.

Cochrane, J. H. (1988), 'How big is the random walk in gnp?', Journal of Political Economy 96, 893-920.

Conrad, J. \& Kaul, G. (1988), 'Time-variation in expected returns', Journal of Business 61, 409-425. 
Conrad, J. \& Kaul, G. (1993), 'Long-term market overreaction or biases in computed returns?', Journal of Finance 48, 39-64.

De Bondt, W. F. M. (1991), 'What do economists know about the stock market?', Journal of Portfolio Management (Winter Issue), 84-91.

De Bondt, W. F. M. \& Thaler, R. H. (1985), 'Does the stock market overreact?', Journal of Finance 40, 793-805.

De Bondt, W. F. M. \& Thaler, R. H. (1987), 'Further evidence on investor overreaction and stock market seasonality', Journal of Finance 42, 557-581.

Fama, E. F. (1991), 'Efficient capital markets: II', Journal of Finance 46, 1575-1617.

Fama, E. F. \& French, K. R. (1988a), 'Dividend yields and expected stock returns', Journal of Financial Economics 22, 3-25.

Fama, E. F. \& French, K. R. (1988b), 'Permanent and temporary components of stock prices', Journal of Political Economy 96, 246-273.

Gangopadhyay, P. \& Reinganum, M. R. (1996), 'Interpreting mean reversion in stock returns', The Quarterly Review of Economics and Finance 36, 377-394.

Gordon, M. J. (1959), 'Dividends, earnings and stock prices', Review of Economics and Statistics 41, 99105.

Goyal, A. \& Welch, I. (2008), 'A comprehensive look at the empirical performance of equity premium prediction', Review of Financial Studies 21, 1455-1508.

Gropp, J. (2004), 'Mean reversion of industry stock returns in the U.S., 1926-1998', Journal of Empirical Finance 11, 537-551.

Hansen, L. P. \& Hodrick, R. J. (1980), 'Forward exchange rates as optimal predictors of future spot rates: An econometric analysis', Journal of Political Economy 88, 829-853. 
Ho, C.-C. \& Sears, R. S. (2004), 'Dividend yields and expected stock returns', Quarterly Journal of Business \& Economics 45, 91-112.

Hodrick, R. J. (1992), 'Dividend yields and expected stock returns: alternative procedures for inference and measurement', Review of Financial Studies 5, 357-286.

Jegadeesh, N. (1991), 'Seasonality in stock price mean reversion: Evidence from the U.S. and the U.K', Journal of Finance 46, 1427-1444.

Kim, C.-J. \& Nelson, C. R. (1998), 'Testing for mean reversion in heteroskedastic data II: Autoregression tests based on Gibbs-sampling-augmented randomization', Journal of Empirical Finance 5, 385-396.

Kim, C.-J., Nelson, C. R. \& Startz, R. (1998), 'Testing for mean reversion in heteroskedastic data based on Gibbs-sampling-augmented randomization', Journal of Empirical Finance 5, 131-154.

Kim, J. H., Silvapulle, P. \& Hyndman, R. J. (2007), 'Half-life estimation based on the bias-corrected bootstrap: A highest density region approach', Computational Statistics and Data Analysis 51, 34183432.

Kim, M. J., Nelson, C. R. \& Startz, R. (1991), 'Mean reversion in stock prices? a reappraisal of the empirical evidence', Review of Economic Studies 58, 515-528.

McQueen, G. (1992), 'Long-horizon mean-reverting stock prices revisited', Journal of Financial and Quantitative Analysis 27, 1-18.

Pastor, L. \& Stambaugh, R. F. (2009), 'Predictive systems: Living with imperfect predictors', Journal of Finance 64, 1583-1628.

Pastor, L. \& Stambaugh, R. F. (2011), 'Are stocks really less volatile in the long run?', Forthcoming Journal of Finance . 
Poterba, J. M. \& Summers, L. H. (1988), 'Mean reversion in stock prices: Evidence and implications', Journal of Financial Economics 22, 27-59.

Richardson, M. \& Smith, T. (1991), 'Tests of financial models in the presence of overlapping observations', Review of Financial Studies 4, 227-254.

Richardson, M. \& Stock, J. H. (1990), Drawing inferences from statistics based on multiyear asset returns, NBER working papers, National Bureau of Economic Research.

Spierdijk, L., Bikker, J. A. \& Van den Hoek, P. (2012), 'Mean reversion in international stock markets: An empirical analysis of the 20th century', Journal of International Money and Finance 31, 228-249.

Summers, L. H. (1986), 'Does the stock market rationality reflect fundamental values?', Journal of Finance 41, 591-601.

Vlaar, P. (2005), Defined benefit pension plans and regulation, DNB working papers, Dutch Central Bank, Research Department.

Zarowin, P. (1990), 'Size, seasonality, and stock market overreaction', Journal of Financial and Quantitative Analysis 25, 113-125. 


\section{Figure 1: Example of a non-stationary mean-reverting process}

The dashed line is a stylized representation of the fundamental value process, which increases over time. The oscillating curve represents the stylized mean-reverting price process, which mean-reverts around the non-stationary fundamental value process.

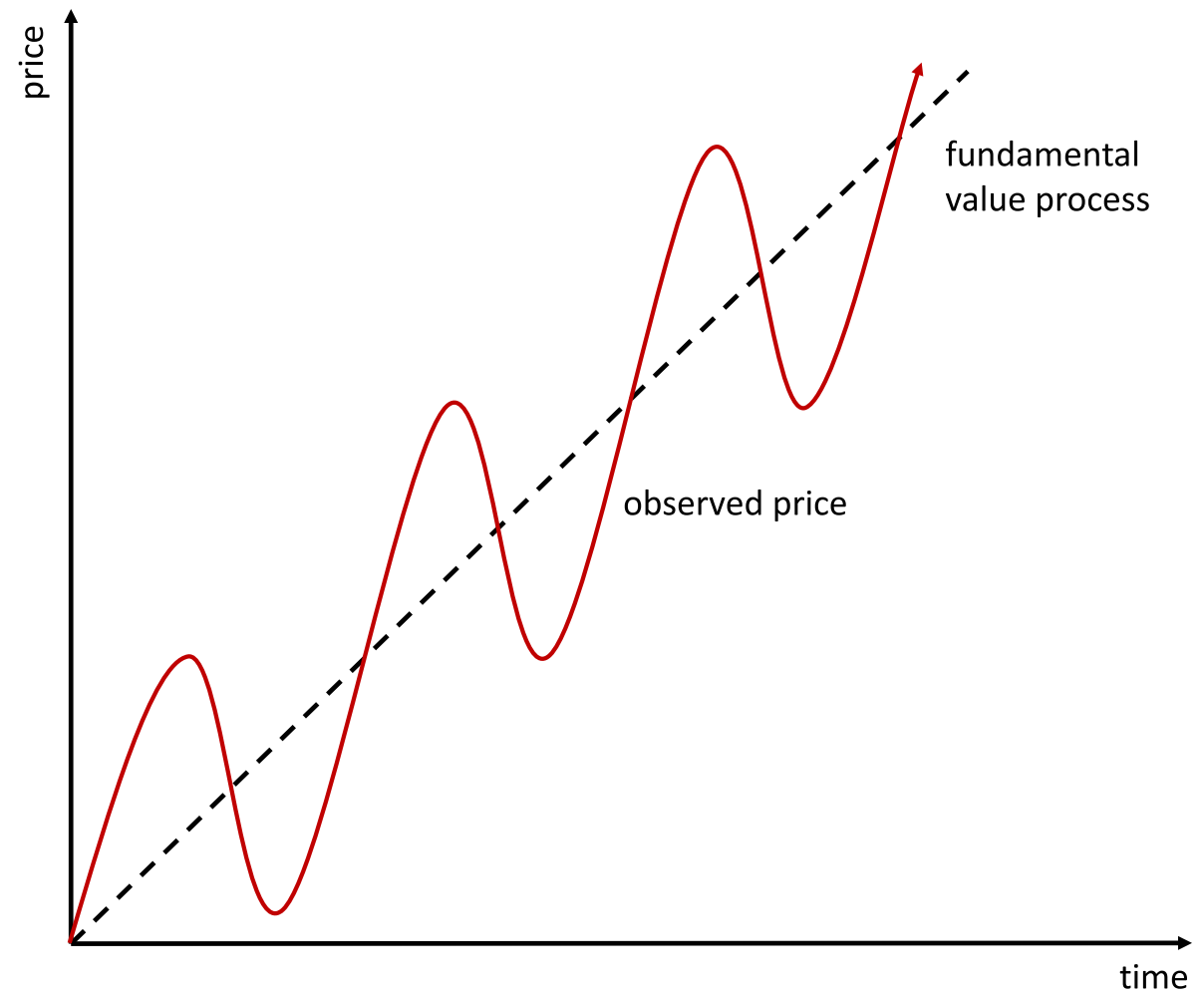




\section{Figure 2: Mean-variance efficient portfolios}

The colored area in this figure represents, in a stylized way, the set of all possible portfolios. The horizontal axis gives the portfolio volatility, whereas the vertical axis provides the expected portfolio return. The solid curve that starts in the global minimum variance portfolio (GMVP) and that marks the upper side of the colored area is the mean-variance efficient set which comprises all mean-variance efficient portfolios. A portfolio is mean-variance efficient if it has the highest expected return, given a certain volatility level or if it has minimum volatility for a given level of the expected return. Two mean-variance efficient portfolios are explicitly highlighted: the global minimum variance portfolio (GMVP) and the tangency portfolio (TP). The former is the mean-variance efficient portfolio with the lowest volatility, whereas the latter is the mean-variance efficient portfolio with highest possible risk-adjusted excess return. The risk-adjusted excess return is the expected excess return divided by the volatility, also known as the Sharpe ratio. The tangency portfolio is obtained by drawing a straight line from the risk-free rate (denoted $r_{f}$ on the vertical axis) tangent to the mean-variance efficient frontier.

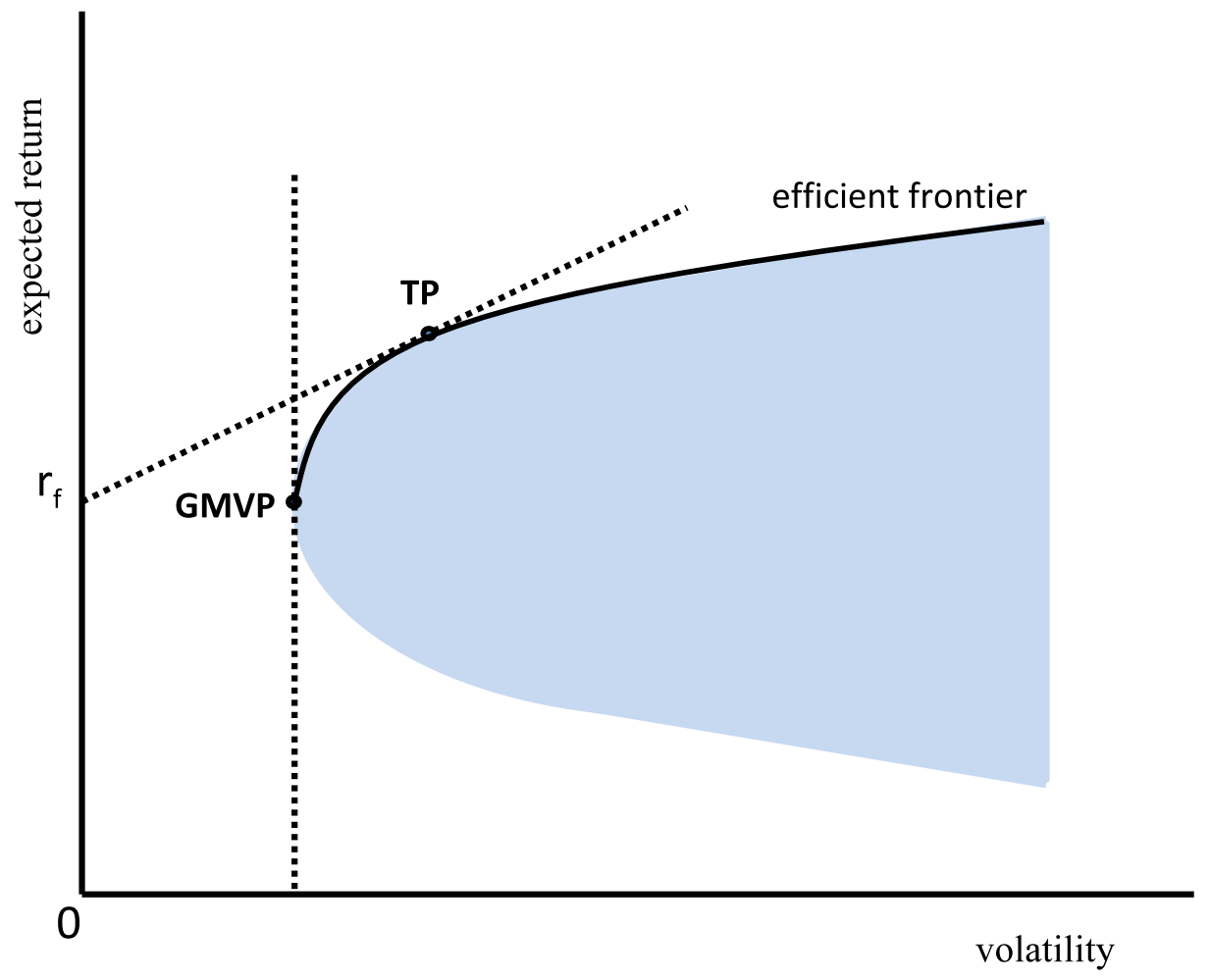


Table 1: Optimal portfolio weights (in percentage) with and without mean reversion in stock prices

This table reports the optimal portfolio weights for the global minimum variance portfolio (GMVP) and the tangency portfolio (TP). The investment categories are stocks (Datastream U.S. Aggregate Stock Market Index) and bonds (Citigroup U.S. Overall Bond Investment Grade Total Return Index) for different values of the variance ratio. The variance ratio is defined as the return variance of the permanent price component divided by the return variance of the transitory component. The risk-free rate is based on the nominal interest rate term-structure as compiled by the Dutch Central Bank. The last two columns in each panel display the expected portfolio return $\left(\mu_{p}\right)$ and the portfolio volatility $\left(\sigma_{p}\right)$.

\begin{tabular}{|c|c|c|c|c|c|c|c|c|c|c|c|c|}
\hline \multirow{4}{*}{ GMV } & \multicolumn{4}{|c|}{ variance ratio $=1: 1$} & \multicolumn{4}{|c|}{ variance ratio $=1: 2$} & \multicolumn{4}{|c|}{ variance ratio $=1: 3$} \\
\hline & $w_{s}$ & $w_{b}$ & $\mu_{p}$ & $\sigma_{p}$ & $w_{s}$ & $w_{b}$ & $\mu_{p}$ & $\sigma_{p}$ & $w_{s}$ & $w_{b}$ & $\mu_{p}$ & $\sigma_{p}$ \\
\hline & \multicolumn{4}{|c|}{ with mean reversion } & \multicolumn{4}{|c|}{ with mean reversion } & \multicolumn{4}{|c|}{ with mean reversion } \\
\hline & & & & & & & & & & & & \\
\hline 1 year & 4.36 & 95.64 & 8.50 & 4.80 & 4.44 & 95.56 & 8.51 & 4.80 & 4.48 & 95.52 & 8.51 & 4.80 \\
\hline 5 years & 5.37 & 94.63 & 42.64 & 10.70 & 5.73 & 94.27 & 42.69 & 10.69 & 5.93 & 94.07 & 42.71 & 10.68 \\
\hline 10 years & 5.86 & 94.14 & 85.41 & 15.11 & 6.45 & 93.55 & 15.08 & 14.90 & 6.79 & 93.21 & 85.63 & 15.06 \\
\hline 20 years & 6.26 & 93.74 & 171.00 & 21.34 & 7.07 & 92.93 & 171.39 & 21.27 & 7.54 & 92.46 & 171.62 & 21.24 \\
\hline \multicolumn{13}{|l|}{ TP } \\
\hline 1 year & 7.20 & 92.80 & 8.57 & 4.82 & 7.30 & 92.70 & 8.58 & 4.82 & 7.36 & 92.64 & 8.58 & 4.82 \\
\hline 5 years & 8.40 & 91.60 & 43.01 & 10.75 & 8.88 & 91.12 & 43.07 & 10.74 & 9.14 & 90.86 & 43.10 & 10.73 \\
\hline 10 years & 9.05 & 90.95 & 86.17 & 15.18 & 9.83 & 90.17 & 86.36 & 15.15 & 10.27 & 89.73 & 86.46 & 15.13 \\
\hline 20 years & 9.57 & 90.43 & 172.59 & 21.44 & 10.64 & 89.36 & 173.11 & 21.38 & 11.26 & 88.74 & 173.40 & 21.35 \\
\hline & \multicolumn{4}{|c|}{ without mean reversion } & \multicolumn{4}{|c|}{ without mean reversion } & \multicolumn{4}{|c|}{ without mean reversion } \\
\hline GMVP & & & & & & & & & & & & \\
\hline 1 year & 4.14 & 95.86 & 8.50 & 4.81 & 4.14 & 95.86 & 8.50 & 4.81 & 4.14 & 95.86 & 8.50 & 4.81 \\
\hline 5 years & 4.43 & 95.57 & 42.53 & 10.73 & 4.43 & 95.57 & 42.53 & 10.73 & 4.43 & 95.57 & 42.53 & 10.73 \\
\hline 10 years & 4.43 & 95.57 & 85.06 & 15.18 & 4.43 & 95.57 & 85.06 & 15.18 & 4.43 & 95.57 & 85.06 & 15.18 \\
\hline 20 years & 4.43 & 95.57 & 170.13 & 21.47 & 4.43 & 95.57 & 170.13 & 21.47 & 4.43 & 95.57 & 170.13 & 21.47 \\
\hline \multicolumn{13}{|l|}{ TP } \\
\hline 1 year & 6.90 & 93.10 & 8.57 & 4.83 & 6.90 & 93.10 & 8.57 & 4.83 & 6.90 & 93.10 & 8.57 & 4.83 \\
\hline 5 years & 7.14 & 92.86 & 42.86 & 10.78 & 7.14 & 92.86 & 42.86 & 10.78 & 7.14 & 92.86 & 42.86 & 10.78 \\
\hline 10 years & 7.14 & 92.86 & 85.71 & 15.24 & 7.14 & 92.86 & 85.71 & 15.24 & 7.14 & 92.86 & 85.71 & 15.24 \\
\hline 20 years & 7.13 & 92.87 & 171.42 & 21.55 & 7.13 & 92.87 & 171.42 & 21.55 & 7.13 & 92.87 & 171.42 & 21.55 \\
\hline
\end{tabular}


Table 2: Expected portfolio return and portfolio risk (in percentage) with and without mean reversion in stock prices

This table reports the expected portfolio return $\left(\mu_{p}\right)$ and the portfolio risk $\left(\sigma_{p}\right)$ for an equally weighted portfolio, for different values of the variance ratio. The variance ratio is defined as the return variance of the permanent price component divided by the return variance of the transitory component. The two investment categories are stocks (Datastream U.S. Aggregate Stock Market Index) and bonds (Citigroup U.S. Overall Bond Investment Grade Total Return Index). The risk-free rate is based on the nominal interest rate term-structure as compiled by the Dutch Central Bank.

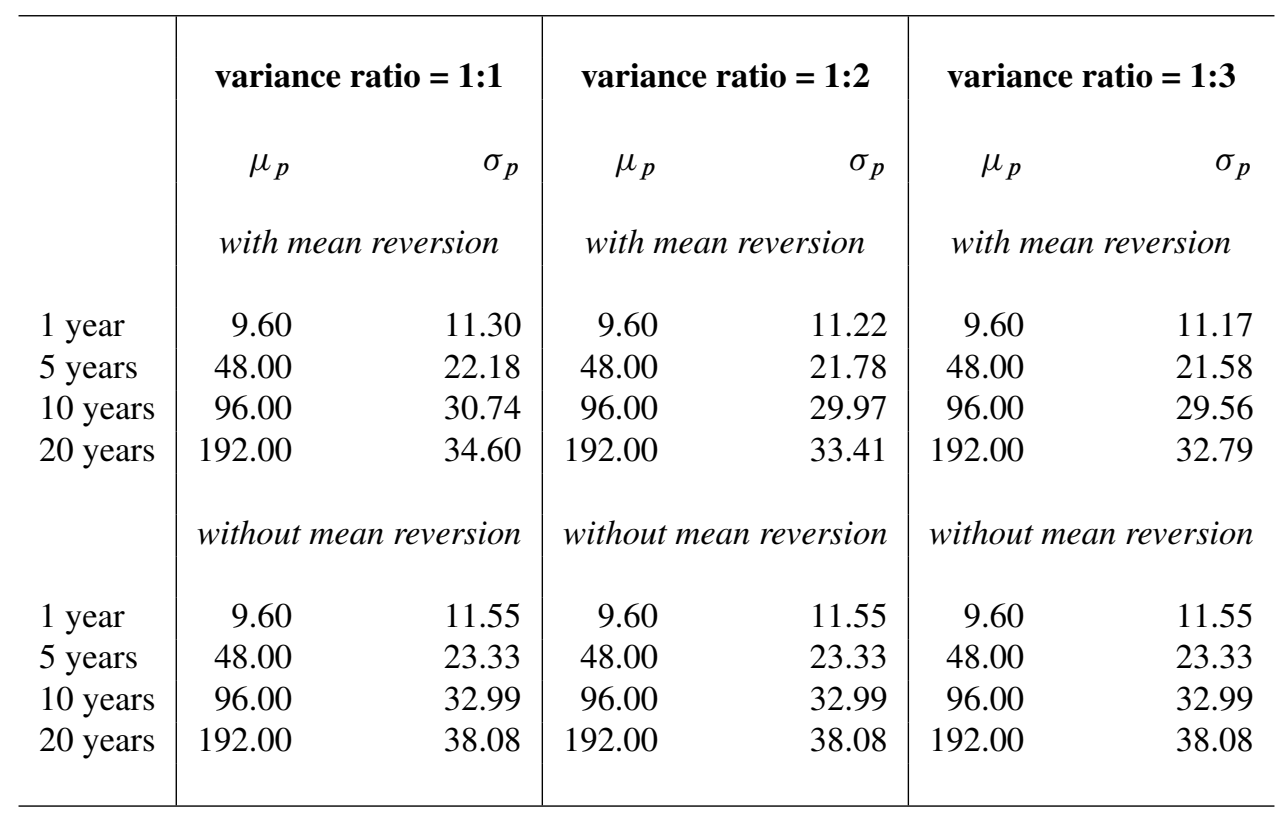

